\title{
The Need for Quality Control and Assurance in Local Food
}

\section{Processing}

\section{Ukwuru MU* \\ Department of Food Science and Technology, Federal Polytechnic, Nigeria}

*Corresponding author: Michael U Ukwuru, Department of Food Science and Technology, Federal Polytechnic, Idah, P.M.B. 1037, Idah, Kogi State, Nigeria, Tel: 08069078818; 08059430991; Email: mikeukwuru@gmail.com

\section{Mini Review}

Volume 3 Issue 1

Received Date: February 25, 2018

Published Date: March 06, 2018

\section{Mini Review}

Abbreviations: HACCP: Hazard Analysis and Critical Control Point; QC: Quality Control; QA: Quality Assurance; GMP: Good Manufacturing Practices; GLP: Good Labeling Practices; GHP: Good Hygienic Practices; ISO: International Organization for Standardization

The objectives of Quality control and assurance is to ensure that a food product meets a particular set of standards with respect to the product itself as well as the processes of production, distribution and processing,. In food quality control, conformance to standard exists and in quality assurance, planned and systematic activities are used to prevent mistakes or defects in manufactured food products. However, systems like Hazard Analysis and Critical Control Point (HACCP) is not applicable in local food processing. Most Local food processing lack quality control and quality assurance in the sense that there are no utilization of technological, physical, chemical, microbiological, nutritional and sensory parameters to achieve the wholesomeness of foods The processors (handlers) are not trained and the raw materials, equipment used, product in process and the finished products are not evaluated to ascertain their freedom from hazards and other food contaminants.

The absence of quality control and quality assurance in local food processing is a matter of concern to food safety. The effect of lack of Quality control (QC) and Quality assurance $(\mathrm{QA})$ in local food processing are: The absence of a national food processing policy, different quality standards, inadequate availability of quality raw material, poor packaging and labeling, inadequate laboratory facilities for certification of quality, lack of application of quality control systems, e.g. HACCP, Good Manufacturing Practices (GMP), Good Hygienic Practices (GHP), Good Labeling Practices (GLP), International Organization for Standardization (ISO) etc, Others include improper packaging, labeling warehousing and transportation, insufficient hygiene and sanitation in food industry, lack of awareness on food quality, low demands and status when compared to imported foods of lower nutritional qualities, limited scientific interests.

In local food processing environment, factors such as temperature, humidity, $\mathrm{pH}$ and biological factors such as pests, rodents are not controlled and regulated. The processing of many local foods remain a household art. They are typically uncontrolled and dependent on microorganisms from the environment. There are no regulatory bodies or government agencies responsible for the standards required in every processing environment (plant). The processing environment is untidy, full of chemical, biological and environmental hazards and other contaminants dangerous for human consumption.

The conditions under which some local food processors operate are reported to be unsuitable for the preparation and processing of foods. The food is prepared either at home close to the bush or untidy environment where wood, polythene bags, tin etc are used. The place of processing is not always clean, not well lit and not far from sources of food contamination. Processing surfaces used by some processors have remains of food prepared earlier that can promote cross contamination. Most of these foods are not covered and are exposed to flies and dust, which may harbor food borne pathogens. In 70 $90 \%$ of the cases, presence of animals, insects and liquid 


\section{Food Science and Nutrition Technology}

wastes in food processing areas have been reported, FAO, (1988).

The equipment used in the processing of local foods is crude and outdated. The process used for local foods involve small-scale grass-root technology. The basic equipment and materials needed in local processing of foods include, local baskets, pans, mortars, pestle, wooden sieves, earthen pots, cooking hearth, buckets without cover, heavy stones, sacs and other locally made rudimentary equipment depending on the food processed and the geographical area. The equipment is not regulated by any regulatory body or agency to establish its conformance to standard and this is a source of contamination to foods.

The handlers of local foods or those responsible for the processing of foods locally are supposed to handle both packaged and unpackaged foods, raw food (raw material) and finished products carefully to avoid contamination but the handlers of local foods are not trained and educated to know the needs for good hygienic practices and food safety. Foods are handled carelessly without any consideration for safety and this has a dangerous effect to the consumers of food. Unsanitary handling of local foods by the some of the processor has been commonly found to be the source of contamination Dawson and Canet (1991). The processors can be carriers of pathogens like Escherichia coli, Samonella, Shigella, Campylobacter and S. aureus who eventually transfer these food-borne hazards to the consumers. The hands of the food handlers are the most important vehicle for the transfer of microorganisms from faeces, nose and skin to the food. The finding that Salmonella, non- typhi Samonellae, Campyobacter and E. coli can survive on finger tips and other surfaces for varying periods of time is a pointer to the cross contamination between food and the consumers.

The government of many nations where these unsanitary handling of foods are prevalent should make effort for food safety campaigns and other forms of enlightenment programs that will educate local food processors on the modalities to handle foods during processing. Similarly, considering the huge population of people that consume these processed foods, it is therefore expedient on the government to institute a kind of regulations aimed at quality control and quality assurance for local food processors

Quality control and quality assurance play important roles in food processing as they help to present food to the consumer in a wholesome state and without any health hazard. It also provide information on process capability and facilities, managerial decisions on expenditure necessary to maintain a desired quality level, quality development or any necessary quality improvement efforts in order that production and services are at the most economical level to allow for full consumers acceptance with satisfaction. Quality assurance ensures that a food product meets a particular set of standards with respect to the product itself as well as the process of production, distribution and processing.

As quality control and quality assurance help reduce the risk of food borne diseases by ensuring standard for each food, it is necessary to educate the local food processors by the need for quality control and quality assurance as applicable in food production to ensure food safety and wholesomeness. 